Revista Estudios, (36), 2018.

Junio 2018-Noviembre 2018

ISSN 1659-3316

Briones Yela Roberto Johann

V Sección

Dossier: Repensar las humanidades: una tarea permanente

\title{
La razón poética de María Zambrano frente a las visiones del Humanismo Moderno
}

Roberto Johann Briones Yela Universidad Politécnica Salesiana, Ecuador rbrionesy@ups.edu.ec

https://orcid.org/0000-0003-2351-316X

Filósofo es aquel que sabe lo que tiene que pensar

Recibido: 29 de marzo de 2018

Aceptado: 28 de abril de 2018

\section{RESUMEN}

María Zambrano buscó incesantemente -a través de sus múltiples escritos-, demostrar que la razón no puede prescindir de la dimensión trascendental innata en el ser humano. El presente trabajo, con las disculpas respectivas hacia los eruditos en la filosofía y la historia de María Zambrano, presenta la razón poética como camino filosófico y pedagógico para alcanzar la trascendencia. Los más grandes estudiosos del mundo, se valieron de dichas categorías para buscar trascender. En nuestro caso y para no perdernos en las marismas de tantas geniales ideologías, analizamos el trabajo de María Zambrano y su razón poética proponiendo un cambio de paradigmas humanísticos, desde el mostrar filosofías pre y pos humanistas hasta entremezclar la filosofía vivencial de María Zambrano, para alcanzar una actitud filosófica donde prevalezca el pensar para ser, antes que el ser para tener.

PALABRAS CLAVE: María Zambrano; humanismo; razón poética; trascendencia; ser

\section{(C) $(00$}

La Revista Estudios es editada por la Universidad de Costa Rica y se distribuye bajo una Licencia Creative Commons Atribución-NoComercial-CompartirIgual 3.0 Costa Rica. Para más información envíe un mensaje a 
"The poetic reason of María Zambrano opposite visions of Modern Humanism"

\section{ABSTRACT}

María Zambrano sought ceaselessly - through his many writings - demonstrate that the reason not do without the innate transcendental dimension in human. This work, with the respective apologies to scholars in philosophy and the history of María Zambrano, presents the poetic reason as philosophical and pedagogical path to achieve transcendence. The greatest scholars of the world, is earned from these categories to find transcend. In our case, and not to get lost in the marshes of so many great ideologies, analyze the work of María Zambrano and his poetic reason proposing a humanistic paradigm shift, since the show philosophies preand humanists to intersperse the experiential philosophy of María Zambrano, to reach a philosophical attitude which prevails the thought to be, rather than to have.

KEY WORDS: María Zambrano; humanism; poetic reason; transcendence; be

\section{Introducción}

Vivimos en tiempos de filosofías «humanistas» y estas, intentan dar puntos de vista para entender y dar respuesta a la política, la ética, la sociología, la psicología y también a la pedagogía. Desde esa perspectiva, es necesario generar un análisis de cuánto influye la filosofía en el humanismo y este, a su vez por la injerencia en las ciencias, en la cotidianidad del hombre. Esta temática se hace importante desde que venimos considerados "seres humanos", categoría primaria sobre la faz de la tierra y estirpe única que genera procesos racionales complejos.

Indudablemente en esta cotidianidad, la vida puede parecer injusta -y por ende se podría afirmar que existe «des-humanismo»-, pues aquellos que tienen oportunidades, no siempre las aprovechan, mientras que aquellos que pueden aprovecharlas, casi nunca tienen ni los medios ni el tiempo para hacerlo. Pasa lo mismo con el aprendizaje de la filosofía y con el aprendizaje en general: aquellos que tienen oportunidades para adentrarse en el vasto mundo del aprendizaje -

\section{(c) (i)(2)}

La Revista Estudios es editada por la Universidad de Costa Rica y se distribuye bajo una Licencia Creative Commons Atribución-NoComercial-CompartirIgual 3.0 Costa Rica. Para más información envíe un mensaje a 
filosófico o no-, puede que no aprecien las posibilidades y terminen sucumbiendo, más bien, al facilismo de la vida y su comprensión efímera y parca; mientras que aquellos que pueden, desean y están dispuestos a cualquier sacrificio por alcanzar el "amor a la sabiduría", carecen de oportunidades.

Por ello, vale la pena citar un párrafo del texto “¿Qué significa pensar?” de Martin Heidegger, al respecto de este tema: [...] "el aprender no se puede lograr a fuerza de regaños y, sin embargo, en ocasiones uno tiene que alzar la voz mientras está enseñando. Hasta tiene que gritar y gritar, aun donde se trata de hacer aprender un asunto tan silencioso como es el pensar (Heidegger M. \&., 2005).

El método utilizado en el presente trabajo, es el análisis crítico filosófico, basándose en autores contemporáneos que hacen un análisis de la realidad en los momentos actuales, donde la visión sobre el ser -humano- ha cambiado de manera drástica.

La afirmación de Heidegger, recuerda la cotidianidad de la academia hoy al hablar de humanismo a los destinatarios: una experiencia donde nos esforzamos por investigar, analizar, concluir y construir cosas nuevas en cuanto al aprendizaje y la búsqueda del conocimiento del ser, solo para darnos cuenta de que a muchos aprendientes no les interesa o creen que no les sirve, por ser "otros" sus problemas de fondo y sus necesidades a futuro. Obviamente si el deseo de aprender viene abandonado, por ende, se aísla el deseo de conocimiento, científico, filosófico y humano. ¿Qué podemos decir entonces del deseo de enseñar a pensar para entender el hombre? o, ¿Por qué es tan difícil motivar al hombre de hoy que aprenda a pensarse?; según Nietzsche, porque vivimos "pensando en el eterno retorno de lo Mismo" (Nietzsche, 1973) y este retorno -es nuestra idea-, se da fundamentalmente porque creemos firmemente en que el sentido de la vida está en el «tener» antes que en el «ser», ergo, vivimos cansados luchando por demostrar ciertas circunstancias antes que por construir nuestras posibilidades. Esta es la sociedad moderna y este es el ser humano «hijo» de su época.

\section{(c) (i) (-)}

La Revista Estudios es editada por la Universidad de Costa Rica y se distribuye bajo una Licencia Creative Commons Atribución-NoComercial-CompartirIgual 3.0 Costa Rica. Para más información envíe un mensaje a 
Por ello y frente a los defensores de una nueva modernidad o «posmodernidad», Heidegger lapidariamente manifiesta que "La época moderna no ha tocado a su fin en manera alguna; por el contrario, está entrando recién en los comienzos de su consumación que presumiblemente ha de ser de larga duración” (Heidegger M. \&., 2005), entendiendo por modernidad aquello a lo que Nietzsche llamaba «el desierto» afirmando por esto “jdesventurado el que alberga desiertos!” (Nietzsche, 1973).

Lo que representa hoy la modernidad, bien puede acercarse al pensamiento de Byung-Chul Han, filósofo y ensayista surcoreano quien usa una muy simbólica comparación -sobre la situación de desesperación en la que se encuentra el ser humano-, cuando afirma que:

“El mito de Prometeo puede reinterpretarse considerándolo una escena del aparato psíquico del sujeto de rendimiento contemporáneo, que se violenta a sí mismo, que está en guerra consigo mismo. En realidad, el sujeto de rendimiento, que se cree en libertad, se halla tan encadenado como Prometeo. El águila que devora su hígado en constante crecimiento es su álter ego, con el cual está en guerra. Así visto, la relación de Prometeo y el águila es una relación consigo mismo, una relación de auto-explotación. El dolor del hígado, que en sí es indoloro, es el cansancio. De esta manera, Prometeo, como sujeto de auto-explotación, se vuelve presa de un cansancio infinito. Es la figura originaria de la sociedad del cansancio" (Han, 2012).

El autor, hace una descripción de la cotidianidad humana: una rueda de la fortuna que gira y gira sin parar, deshaciendo la idea de que la idea de vida es lineal.

Al abordar lo que él llama «aparato psíquico del sujeto de rendimiento contemporáneo» no hace otra cosa que recordarnos que vivimos en una época donde lo que cuenta para el hombre es la cantidad de dinero y poder que maneja, no cuánto ha logrado entender de su vida o si ha llegado al pleno conocimiento de su ser. A esto súmesele la idea de «auto-explotación» que impera en las

\section{(c) (i) (-)}

La Revista Estudios es editada por la Universidad de Costa Rica y se distribuye bajo una Licencia Creative Commons Atribución-NoComercial-CompartirIgual 3.0 Costa Rica. Para más información envíe un mensaje a 
Revista Estudios, (36), 2018.

Junio 2018-Noviembre 2018

ISSN 1659-3316

Briones Yela Roberto Johann

personas, con el afán de alcanzar lo que la sociedad quiere que pensemos es progreso.

Es interesante encontrar en un ciudadano asiático, la idea de «auto-explotación», conocedores de que dicha estirpe ancestralmente se ha sometido a emperadores, reyes y últimamente a «presidentes», debiendo -un poco para romper con este modelo- generarse un proceso de «invasión cultural occidentalizante».

Más adelante, el mismo autor describe estas sociedades,

"La sociedad disciplinaria de Foucault, que consta de hospitales, psiquiátricos, cárceles, cuarteles y fábricas, ya no se corresponde con la sociedad de hoy en día. En su lugar se ha establecido desde hace tiempo otra completamente diferente, a saber: una sociedad de gimnasios, torres de oficinas, bancos, aviones, grandes centros comerciales y laboratorios genéticos. La sociedad del siglo XXI ya no es disciplinaria, sino una sociedad de rendimiento. Tampoco sus habitantes se llaman ya «sujetos de obediencia», sino «sujetos de rendimiento». Estos sujetos son emprendedores de sí mismos. Aquellos muros de las instituciones disciplinarias, que delimitan el espacio entre lo normal y lo anormal, tienen un efecto arcaico" (Han, 2012).

Estamos frente a una sociedad nueva, donde incluso la palabra «humanismo», viene forzada a reinterpretarse. Desde luego en el presente trabajo, no se pretende demostrar si a esto se puede llamar modernidad o no, o si nuestros autores están en lo correcto, pero es importante destacar que ya ellos, se planteaban la idea de que el hombre moderno -si no comienza a pensar desde un humanismo humano-, viviría en el desierto de sus propias circunstancias, y esto a su vez lo llevaría al «sin sentido».

Por ello, cuando nos referimos a trascendencia en este trabajo, nos referimos al enfrentamiento entre lo intrascendente de la cotidianidad humana -el sin sentido visto e intentando reflexionar en los preámbulos-, y lo trascendente del vivir humano -pensar para ser, eje transversal en el que se convierte la poesía-. Lo

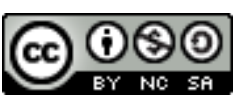

La Revista Estudios es editada por la Universidad de Costa Rica y se distribuye bajo una Licencia Creative Commons Atribución-NoComercial-CompartirIgual 3.0 Costa Rica. Para más información envíe un mensaje a revistaestudios.eeg@ucr.ac.cr. 
uno desde luego, tiene que ver con cómo vivimos la vida y lo segundo con cómo respondemos a las posibilidades que se nos presentan para existir.

Jorge Larrosa -al respecto del pensamiento dominante en el mundo del conocimiento y que constituye la raíz desde donde se gesta la ideología modernaafirma que “...para entender la estructura profunda de una práctica institucional hay que interrogarse por lo que prohíbe, desde aquí se podrá conocer cómo funcionan las estructuras de producción, transmisión y control del conocimiento" (Larrosa, 2003). ¿Lo que prohíben las instituciones entonces, es pensar, llegar a conocerse? Para Larrosa, los dispositivos de control del saber son también dispositivos de control del lenguaje y de nuestra relación con el lenguaje o, dicho de otra manera; cómo y qué leemos, escribimos, hablamos y escuchamos; y no solo eso, pues continúa “...esto, puede llevar al temor para una persona que tenga pretensiones de escribir de filosofía o poesía, cuando alguien -presumiblemente docto-, le diga <eso que escribe usted no es filosofía/poesía>. Dicho reproche lo escuchó Nietzsche, Foucault o el mismo Heidegger, personas que modificaron completamente, lo que hoy entendemos por filosofía o poesía" (Larrosa, 2003), o sea que las estructuras de producción -y se las menciona constantemente en este apartado, por su estrecha vinculación con las categorías de conocimiento y su dependencia extrema para el hombre de hoy-, también buscarían entrometerse en el por qué leemos, escribimos, hablamos y escuchamos, llegando incluso a desdeñar aquello que para tal, no es "ciencia".

Ante ello Larrosa añade “...en el mundo académico, la gente está cada vez más aburrida de oír siempre las mismas cosas, dichas en el mismo registro arrogante y monótono, generando una cierta expectativa hacia cualquier registro de escritura que se presente al menos como distinto" (Larrosa, 2003).

Estamos frente a un fenómeno que ya venía presagiando María Zambrano cuando rompe con su maestro Ortega para fijar definitivamente su propio camino: pasar de una Razón Vital, que privilegia la vida como superación de la razón pura kantiana

\section{(c) (i) (-)}

La Revista Estudios es editada por la Universidad de Costa Rica y se distribuye bajo una Licencia Creative Commons Atribución-NoComercial-CompartirIgual 3.0 Costa Rica. Para más información envíe un mensaje a 
-pero que no es suficiente-, a una Razón donde la Poesía le permita al hombre realizarse y construir su propia personalidad, esta es la percepción de Zambrano. Ahora bien, ¿hasta qué punto coinciden?; con toda probabilidad en la experiencia primera del pensamiento orteguiano, lo que la dota de una fisonomía intelectual, de rasgos propios de su pensar. Luego, sus caminos, racionalidad y preocupaciones, se separan notablemente.

En este entorno (temporal) de pérdida de sentido y con esta visión de sociedad, se encuentra María Zambrano (1904), estudiosa veleño-malagueña, hija de pedagogos y para quien el hombre, no es simplemente un ser histórico, sino que es un ser destinado a trascender y a trascenderse. Pensadora, ensayista, educadora, pero sobretodo, filósofa; María Zambrano vivió siempre entre el compromiso político hacia su tierra, el deseo de hacer de la filosofía una ciencia que lleve a la trascendencia y el pensamiento poético, fruto de la relación entre el hombre y lo divino.

Para Zambrano, el hombre está dotado de una sustancia en su interior: el Ser. Ese «Ser» son sus sentimientos, sus ideas más profundas; lo más sagrado del yo y de su conciencia, "....pues aparece desde el primer día que existimos aún sin ser conscientes" y "...se va creando poco a poco en cuanto nos surgen dudas y, a través de estas sustancias, debe buscar su unidad como persona (Zambrano, 2016). Su arduo deseo de cambiar la historia la llevó a salir de España durante la «Diáspora intelectual española» (1936-1939) -durante la Guerra Civil Española; por motivos políticos e ideológicos, muchos egregios ciudadanos españoles se vieron forzados a desplazarse a otros países bajo el riesgo de represalias de parte del régimen político autoritario instaurado por Franco, algunos pensadores de la Escuela de Madrid, no fueron la excepción-, instalándose momentáneamente en algunos países latinoamericanos (Chile al inicio, luego México y finalmente Cuba), para poder seguir «pensando» y entregando los aportes de su visión a través de sendos escritos filosófico-poéticos. Durante este tiempo, no deja de seguir de

\section{(c) (i) (2)}

La Revista Estudios es editada por la Universidad de Costa Rica y se distribuye bajo una Licencia Creative Commons Atribución-NoComercial-CompartirIgual 3.0 Costa Rica. Para más información envíe un mensaje a 
Revista Estudios, (36), 2018.

Junio 2018-Noviembre 2018

ISSN 1659-3316

Briones Yela Roberto Johann

cerca la difícil situación de los pensadores españoles y conoce de primera mano la realidad latinoamericana.

De estas experiencias de vida concluye -entre muchas cosas- que, "...si la filosofía es encontrarse con uno mismo, llegar a poseerse; la tarea de la educación será alcanzar esa finalidad: una realidad trascendente, actualizando nuestra vida desde el universo del triduo sagrado-divino-humano" (Zambrano, 2015).

Desde aquí se puede ir comprendiendo que, para Zambrano, en la educación están las respuestas a los múltiples conflictos que le toca afrontar al ser.

Su visión de educación no es aquella adoctrinante que conocemos y que la humanidad ha sufrido desde las primeras prácticas «educativas» de la Universidad de Bolonia; sino que María Zambrano proyecta una visión fresca -herética para los pedagogos de su época y aún más para los modernos-que parte del entender la vocación:

"Todas las vocaciones tienen algo en común, sin duda alguna. El ahondar en ese luminoso fenómeno, exige todo un tratado, pero es más todavía un sistema de pensamiento desde el cual la vocación aparezca como algo inteligible; como uno de esos inteligibles que no solamente se entienden, sino que hacen entender. Y la mayor parte de las ideologías del mundo moderno, incluidos algunos sistemas filosóficos, no dejan lugar siquiera a que se tenga en cuenta el hecho de la vocación; es más, ni siquiera la palabra misma puede ser usada" (Zambrano, 2015).

Es interesante leer que Zambrano diferencia «vocación» de «profesión». Sobre lo primero afirma que para que aparezca, se necesita un sistema de pensamiento que deje lugar al individuo -tesis zambraniana que busca la realización y la construcción del hombre como individuo-, lo que equivaldría a decir su libertad.

De lo segundo -profesión-, Zambrano dice que esto es equivalente a términos vacíos como ocupación o simple «trabajar para ganarse la vida» (Sanchez-Gey J.

\section{(c) (1) (2)}

La Revista Estudios es editada por la Universidad de Costa Rica y se distribuye bajo una Licencia Creative Commons Atribución-NoComercial-CompartirIgual 3.0 Costa Rica. Para más información envíe un mensaje a revistaestudios.eeg@ucr.ac.cr. 
Revista Estudios, (36), 2018.

Junio 2018-Noviembre 2018

ISSN 1659-3316

Briones Yela Roberto Johann

\&., 2011), cosa sobre la que tratamos en un principio y que permite ir entendiendo el porqué de su visión vocacional-poética.

\section{Sobre la persona, centro del humanismo}

Para María Zambrano, la persona es una realidad inacabada, inconclusa o en formación, y debe tender a la transparencia, a la trascendencia. Esto implica para el hombre-, dejarse poseer por lo sagrado de la realidad y su verdad. Esta verdad, no es otra cosa que la palabra, el «todo», la que; a medida que el hombre construye su personalidad, va tomando cuerpo, existiendo por sí misma.

En su texto Claros del Bosque, María Zambrano logra mostrar su propia idea de «ser» -vinculándolo desde nuestra óptica con la persona- al afirmar que "El ente solo puede ser, en cuanto ente, si está dentro y más allá de lo iluminado por esa luz que existe en un lugar abierto y que es un claro" (Zambrano, 1977).

Entonces el ser; dentro de esta visión zambraniana, sería el verbo -la palabra-, que habitado por el ente y rodeado por él; contemporáneamente lo mueve, generando vida y luz. Estas, -vida y luz- brillan entregándose y hallándose, iluminándolo todo y yendo más allá.

Por este motivo, la razón zambraniana o razón poética, no puede dejar de entremezclarse constantemente con la vida y sus relaciones, no puede dejar de pensar en su carácter vital, en su vitalidad específica. Desde esta idea, parte la crítica de María Zambrano hacia el triunfo de las filosofías sistémicas -intentar desarrollar marcos lógico matemáticos en los cuales los sistemas mentales, cognitivos, metafísicos y filosóficos, puedan ser estudiados- y la razón tecnocientífica, pues ambas llevan a un falso monopolio de la erudición y el conocimiento, como sabiamente afirmaba Nietzsche quien pensaba que el erudito o el especialista, se convierten en «proletarios» del conocimiento, aplastados por la división del trabajo y -obviamente- por la necesidad de producir para el mercado: "El especialista es semejante al obrero de fábrica que durante toda su

\section{(C) $(0 \bigcirc$}

La Revista Estudios es editada por la Universidad de Costa Rica y se distribuye bajo una Licencia Creative Commons Atribución-NoComercial-CompartirIgual 3.0 Costa Rica. Para más información envíe un mensaje a revistaestudios.eeg@ucr.ac.cr. 
vida no ha hecho otra cosa que determinado tornillo para determinado utensilio, en el que indudablemente tendrá increíble maestría, pero ya no está en condiciones de leer por placer" (Nietzsche, 2016).

Para Zambrano, los programas que busquen reformar el entendimiento, el pensamiento o la razón misma, pasarían por hacer violencia a su categoría de vida, haciendo que esta se ajuste a los moldes de la razón. Ante esa violencia, la vida quedaría humillada, pues la razón no debe dominar a la vida, sino que debe enamorarla, sentido primero y último de la poesía.

Por esto, desde la idea central de Martin Heidegger, que "la poesía es el más peligroso de los bienes, pero al mismo tiempo el material de la más inocente de las tareas" (Heidegger, 1992), se puede ir comprendiendo la dimensión esencial del poeta: con sus palabras tiene la capacidad única de destruir, pero también existe en él la capacidad, única también, de crear. Y esta capacidad es la que le permite acercarse a lo que Zambrano entiende por trascendencia: lo ajeno al tiempo y lo sometido a él; la historia.

El ente heideggeriano, se mostraría -entonces- cuando aparece la palabra hecha poesía, y esto solo se da mediante la manifestación pura del ser, la verdad.

Y esto el autor lo deduce afirmando que la poesía de Hölderlin, "está cargada con la determinación poética de poetizar la propia esencia de la poesía" (Heidegger M. , 1992) -el autor considera que el ser humano se relaciona con el mundo a través de una poetización, y entiende la «casa» como el lugar donde esta cualidad poética cobra sentido: el hombre habita midiendo lo que está sobre la tierra y lo que está bajo el cielo; de aquí, poetizar sería una forma distinta de ver y de percibir el mundo- desde donde entiende que para ser lo que somos, debemos testimoniar nuestra realidad, dar fe; mediante la experiencia, de que no solo «somos» en el mundo, sino que «estamos presentes» concretamente.

Esta comprensión, bastante cercana al escrito Paulino “...es verdad que vivimos en este mundo, pero no actuamos como todo el mundo..." (AAVV, 2015) lleva a entender la función que por vocación innata hacia la vida, debe tener el poeta.

\section{(c) (i) (-)}

La Revista Estudios es editada por la Universidad de Costa Rica y se distribuye bajo una Licencia Creative Commons Atribución-NoComercial-CompartirIgual 3.0 Costa Rica. Para más información envíe un mensaje a 


\section{La filosofía y el humanismo}

Iniciemos este apartado -que buscará encontrar sustento a lo que se ha venido afirmado hasta ahora-, definiendo filosóficamente los conceptos que entran a debate; filosofía y humanismo.

Según Juan García, la filosofía es:

"Amor a la sabiduría -cosa en la que coinciden innumerables teóricos-, deseo de conocimiento que nos lleva a plantearnos preguntas radicales, cuyas respuestas, sabemos que nunca nos van a satisfacer. Pero, a pesar de saber que nuestra pregunta no va a obtener una respuesta perfecta, la seguimos formulando como si nos viniera impuesta por algo más fuerte que nuestra voluntad, o sea, la pregunta es aquella que necesitamos plantearnos de forma insoslayable" (García, 2000).

Razón tenía María Zambrano cuando afirmaba en uno de sus textos que "Filosófico es el preguntar y poético el hallazgo" (Zambrano, 2004).

Es interesante que, según el Diccionario de Filosofía de José Ferrater Mora, al indagar sobre el término humanismo debemos hacer referencia a ciertas épocas específicas.

1. 1941: por humanismo se entiende a "...la tendencia que durante el Renacimiento produjo el amor y el culto a la Antigüedad clásica, considerada como un ejemplo de afirmación de la independencia del espíritu humano y, por tanto, de su valor autónomo y dignidad" (Ferrater Mora, 2012).

Durante los mismos años, Burckhardt afirma que humanismo “...significa el descubrimiento del hombre en cuanto hombre y, consiguientemente, la reafirmación de todo lo humano, tanto en el sentido del individualismo como en el sentido de la humanidad" (Burckhardt, 2004).

\section{(c) (†) (-)}

La Revista Estudios es editada por la Universidad de Costa Rica y se distribuye bajo una Licencia Creative Commons Atribución-NoComercial-CompartirIgual 3.0 Costa Rica. Para más información envíe un mensaje a revistaestudios.eeg@ucr.ac.cr. 
También Schiller llama humanismo a "...la conversión de toda pretensión de verdad o falsedad en función de los propósitos del hombre" (Schiller, 2009), agregando que; "el humanismo es una ampliación y, a la vez, una superación del pragmatismo, pero la relativización de toda verdad, expresada en el principio de Protágoras por él adoptado no significa la negación de la verdad, sino la atribución de verdad a todo lo que responda a las necesidades humanas de cada individuo" (Schiller, 2009).

2. 1965: "...humanista era el que se consagraba a las artes liberales $y$, dentro de éstas, especialmente a las artes liberales que más en cuenta tienen lo general humano; historia, poesía, retórica, gramática (incluyendo literatura) y filosofía moral" (Kristeller, 1993).

3. Época moderna: Según Ferrater Mora; "En la época actual se ha hablado de humanismo no sólo para designar el movimiento «humanista», sino también, para calificar ciertas tendencias filosóficas, especialmente aquellas en las cuales se pone de relieve algún «ideal humano». Como los «ideales humanos» son muchos, han proliferado los humanismos" (Ferrater Mora, 2012). Se agrega además que "Algunas de estas tendencias humanistas se caracterizan por la insistencia en la noción de «persona», en contraposición a la idea del «individuo»; otras se caracterizan por predicar la «sociedad abierta» contra la «sociedad cerrada»; otras por destacar el carácter fundamental social del ser humano y finalmente algunas, ponen de relieve que el hombre no se reduce a ninguna función determinada, sino que es una totalidad" (Ferrater Mora, 2012).

De su lado, los estructuralistas embistieron contra el humanismo al afirmar que "el humanismo yerra al considerar que el hombre, incluyendo el hombre «totalizado», es el verdadero sujeto de la historia, indicando que la propia «historia», es una manifestación superficial de estructuras profundas, las cuales en vez de ser creadas y llevadas por los hombres, llevan a los hombres" (Ferrater Mora, 2012).

\section{(c) (i)(2)}

La Revista Estudios es editada por la Universidad de Costa Rica y se distribuye bajo una Licencia Creative Commons Atribución-NoComercial-Compartirlgual 3.0 Costa Rica. Para más información envíe un mensaje a 
Revista Estudios, (36), 2018.

Junio 2018-Noviembre 2018

ISSN 1659-3316

Briones Yela Roberto Johann

Algunas impresiones al respecto dejan la confrontación entre lo que; en cuanto al conocimiento, se entiende por filosofía y lo que se entiende -o intenta entender más bien- por humanismo.

Lo primero que hay que mencionar es que el término filosofía no ha evolucionado a través de los siglos. Esto nos da una idea de cuánto ha sido importante para los filósofos, la comprensión de lo que significa el amor por la sabiduría.

Ya lo dice Larrosa, “...entre las formas de escritura derrotadas, vencidas y difícilmente clasificables en las actuales divisiones del saber, se encuentran los ensayos, las epístolas morales, los tratados breves y por supuesto, los diálogos filosóficos” (Larrosa, 2003); y añade, “...simplificando mucho la cuestión, la filosofía de los profesores de filosofía, de la academia universitaria, de aquellas formas de escritura que tenían la capacidad de enamorar a la vida, es decir, de dirigirla desde adentro, ha desaparecido" (Larrosa, 2003).

Y qué decir del concepto de humanismo, cuando desde que se instaura la palabra «humanismo»-1504 véase A. Campana, «The Origin of the Word 'Humanist'», Journal of the Warburg and Courtlauld Institutes, IX [1946], 60-73- han surgido interpretaciones e interpretadores que, según el momento de la historia o el momento personal, le dieron significado y significante.

Del año 41, rescatable el hecho que se vea el humanismo como algo que necesariamente tiene que ver con el hombre, su verdad y el deseo de individualismo, lo cual podríamos llamar «deseo de ser». Sobre esto ya Zambrano intentaba demostrar que el «ente», se muestra cuando aparece la poesía en la palabra, y esta es -necesariamente-, manifestación pura del ser: “...la poesía, es el decir de la des-ocultación del ente, pues todo arte es dejar acontecer el advenimiento de la verdad del ente en cuanto tal, y por lo mismo es en esencia Poesía" (Janés, 1984).

En los años 60 se comienza a notar ya, este impulso por separar lo «humano» del término «humanismo», pues como afirma Kristeller, la palabra adquiere una connotación de «categoría» de la ciencia o «especialización específica».

La Revista Estudios es editada por la Universidad de Costa Rica y se distribuye bajo una Licencia Creative Commons Atribución-NoComercial-CompartirIgual 3.0 Costa Rica. Para más información envíe un mensaje a revistaestudios.eeg@ucr.ac.cr. 
Razón tendrían entonces, Heidegger y muchos más, en plantear el tema de la «ontología», pero que -como afirma Levinás-, "La ontología heideggeriana subordina la relación con el Otro a la relación con el ser en general (aún si se opone a la pasión técnica, salida del olvido del ser oculto por el ente), permanece en la obediencia de lo anónimo y lleva, fatalmente, a otra potencia, a la dominación imperialista, a la tiranía” (Levinas, 2004) Se trata, según entender, de ubicar al ser antes que el ente -y por tanto también la ontología antes que la metafísica-, derivando en un movimiento en el ser mismo antes que en la obligación frente al otro" (Levinas, 2004).

Sobre esto, Víctor Iza, pensador ecuatoriano que ha trabajado mucho la visión ontológica levinasiana, afirma que "No somos capaces de ser por nosotros mismos sin el otro, es el otro quien ha decidido en un momento dado de nuestra existencia por nosotros, -quien- decide al ver nuestro rostro y da respuesta, se «responsiviza»-perteneciente o relativo a la respuesta, que garantiza, da garantías o se hace responsable de la respuesta del otro, que la asume como propia- en un acto de presencia, tal vez de amor, tal vez de responsabilidad" (Iza, 2016), destacando el papel fundamental del «otro» en el conocerse a sí mismo y entenderse como persona, para gestar esa identidad sobre la que predica Zambrano y que le lleva a afirmar que "La palabra es el pensamiento con que el hombre sella su paso por el universo" (Sanchez-Gey J. \&., 2011).

Además, sobre la crisis del hombre moderno añade:

"Los presupuestos económicos que nacieron con los libros 'La riqueza de las naciones' de Adam Smith (1776) y la 'Teoría general sobre el empleo, el interés y el dinero' de John Maynard Keynes (1936) junto con los presupuestos marxistas del 'Capital de Marx' (1867), acompañados con el pragmatismo británico y estadounidense; provocaron una visión del mundo que posiblemente generó en el mundo occidental, un distanciamiento de la alteridad y promovieron un individualismo ligado al confort y la búsqueda de la felicidad como un hito y una utopía" (Iza, 2016).

\section{(c) (i) (2)}

La Revista Estudios es editada por la Universidad de Costa Rica y se distribuye bajo una Licencia Creative Commons Atribución-NoComercial-CompartirIgual 3.0 Costa Rica. Para más información envíe un mensaje a revistaestudios.eeg@ucr.ac.cr. 
Revista Estudios, (36), 2018.

Junio 2018-Noviembre 2018

ISSN 1659-3316

Briones Yela Roberto Johann

Desde aquí, se va gestando ya una visión de «nuevo humanismo» como el que promovía María Zambrano; una visión centrada en la persona que sin el «otro» pierde sentido, pierde su norte. El camino hacia ese reconocimiento está marcado por los escritos de los filósofos llamados «personalistas», quienes se centran en la persona y su relación con el otro, más que en los paradigmas que promueve la sociedad industrializada de hoy.

\section{Neo humanismo: personalismo}

"La vida es la unión de contradicciones, y el hombre mismo está constituido de contradicciones" (Zuluaga, 2015); con esta frase, Conrado Giraldo abre el resumen de su análisis sobre la tragedia en Nietzsche.

Es interesante notar que, en dicho escrito, se hace referencia a la inmortal obra de Nietzsche "El nacimiento de la tragedia" (Niezstche, 2016) que centra su discurso en la experiencia de la vida y muerte, afirmando que todo es uno, que no hay diferencias más que aquellas de carácter práctico. La vida; entonces, sería fuente eterna que constantemente individualiza al ser, pero que; contemporáneamente, se desgarra a sí misma. De aquí que nuestra vida sea constante dolor y sufrimiento y por ello, el hombre la «piensa» como algo trágico.

Pero también la muerte es belleza, pues Giraldo Zuluaga, nos recuerda que entre las fuentes de las cuales Nietzsche «bebió conocimiento", están Schopenhauer y Wagner, el primero filósofo, pero también literato y el segundo, gran compositor que «jugó» a ser filósofo.

Nietzsche buscó sembrar, en sus escritos, esa duda humana sobre la verdad que imponía la sociedad, por ello; cuando escribía, rompía con la lógica de su tiempo sin importarle si esto le era favorable o no. Su idea de raciocinio -distinta de lo tradicional y dogmático-, intenta demostrar lo que Giraldo Zuluaga describe como "el camino del conocimiento, de la liberación, de la vida [...], el de este espectáculo o, más bien, lo que es representado por él: el lugar donde se

\section{(c) (i)(2)}

La Revista Estudios es editada por la Universidad de Costa Rica y se distribuye bajo una Licencia Creative Commons Atribución-NoComercial-CompartirIgual 3.0 Costa Rica. Para más información envíe un mensaje a revistaestudios.eeg@ucr.ac.cr. 
conjugan el sueño y la ebriedad con la vigilia y la sobriedad" (Zuluaga, 2015); y continúa "Nietzsche ve en el fenómeno de lo trágico la verdadera naturaleza de la existencia, del vivir del hombre, con lo que el tema estético adquiere un carácter ontológico: solo el arte y la poesía trágicos son capaces de mostrar la esencia del mundo" (Zuluaga, 2015).

Desde esta afirmación, vemos el por qué Heidegger vuelve siempre la mirada a la obra de Nietzsche y afirma su sentir desde la «inquieta» visión del autor.

Para poder conciliar lo avanzado hasta ahora con la filosofía zambraniana es necesario -es nuestro parecer-, conocer lo que hoy podría llamarse «visiones humanistas modernas» 0 «neo-humanismo».

Hablar de humanismo, necesariamente implica hablar de personalismo. Este es un movimiento/corriente filosófica, que “...pone el énfasis en la persona. Considera al hombre como un ser relacional, esencialmente social y comunitario, libre, trascendente y con un valor en sí mismo que le impide convertirse en un objeto como tal. Un ser moral, capaz de amar, de actuar en función de una actualización de sus potencias y finalmente de definirse a sí mismo considerando siempre la naturaleza que lo determina" (Zambrano, 2015).

¿Zambrano era personalista?, la respuesta es sí, si tomamos en cuenta su preocupación por la persona, su evolución como ser creado y su deseo de que este buscase la trascendencia; la respuesta es no, si leemos al pie de la letra el concepto, cuando se llega a decir: convertirse en un objeto como tal.

Ante esta afirmación que busca objetivizar al ser, Zambrano afirma que "...la vida, es por principio superficial, y solo deja de serlo si a su respiro se une el aliento del ser que, escondido bajo ella, está depositado sobre las aguas primeras de la vida que nuestro vivir apenas roza" (Zambrano, 2015).

Para Zambrano la palabra y la vida fueron creadas la una para la otra, algo así como la frágil flor que necesita necesariamente del agua para subsistir, crecer y robustecerse, sin la cual no encuentra ni vida ni sentido; y no importa que se interpongan reglas, leyes y fundamentos científicos, pues es hacia allá que debe 
avanzar la vida para poder trascender, imagen mismísima de la relación entre el hombre y lo divino.

Por ello, más allá de los conceptos científicos-racionales que el mundo intenta inyectarnos en el cerebro, la vida debe estar vinculada por naturaleza a la visión de lo divino. Esto no implica, desde luego, que el hombre deba estar sujeto a la ideología oprimente de una doctrina u otra, sino más bien a un «sentido último» de esperanza, un espacio donde se permita ver al hombre completo, el de la poesía según Zambrano-; individual y contemporáneamente comunitario, desde y hacia su propia historia universal.

Hasta nuestros días, la razón ha imperado en el conocimiento, ¿dónde lo ha llevado?, ¿dónde ha depositado sus fuentes, sus certezas, sus ideas y pensares? María Zambrano enseña -tuvo mucho que decir sobre el tema del aprendizajeque el filósofo “...no es aquel que solo piensa en el «ser», sino que filósofo es quien busca violentamente el amor, de ahí que no se puede categorizar al filósofo -ni a la filosofía- como humanista, personalista, idealista, etcétera; porque toda filosofía «ES» humanista, en cuanto la sabiduría solo puede ser alcanzada por y para el hombre" (Zambrano, 2016).

El filósofo que alcanza esta comprensión, deja entonces de serlo para ser poeta, y no sigue buscando porque ya tiene «algo», ya encontró la esencia de su ser y estar ahí -el dassein heideggeriano-, se hace uno con el poema, con el ser. No busca nada más, porque teme que en cada cosa no encuentre el «todo» de las cosas. Quiere un «todo» desde el cual se posea cada cosa, pero entendiendo por «cosa», lo complejo, lo inventado por él, su realidad, lo que abarca al ser; pues en el encontrar sentido en los que nos rodea, está el destino concreto del hombre.

En la palabra del poeta, tanto Heidegger, Nietzsche como Zambrano, encuentran esa «respuesta»-generada siempre para la filosofía- al continuo preguntar del hombre: ¿puede la razón sustituir a la vida?

Por esto, María Zambrano, en los epítomes de su obra, pensaba que estaba haciendo «razón vital», dándose cuenta -por fortuna tempranamente- de que lo 
Revista Estudios, (36), 2018.

Junio 2018-Noviembre 2018

ISSN 1659-3316

Briones Yela Roberto Johann

que estaba haciendo era construirle sustento a su razón poética: "no voy a universalizar en conceptos lo concreto, lo singular, pues, además, en lo concreto y singular puede estar depositado, al igual que en el resto, algo de trascendencia" (Zambrano, 2016).

Zambrano propone «rescatar la pasividad despertándola», cuestionando la cultura occidental moderna, carcelera de la conciencia, donde la razón poética deja de morar por impedírselo el habitar entre las «cosas».

"La creencia racionalista en que el mundo está compuesto de cosas, no de acontecimientos; de sustancias y no de sucesos, en que el mundo es estático, fundamentalmente idéntico a sí mismo. Mundo tan dócil que permite el saber a qué atenerse y da a la razón humana, al par que un definitivo rango, una seguridad que excluye casi la aventura" (Sanchez-Gey J. , 2014).

La tarea de la razón, entonces, es lanzarse al laberinto del acontecer, del devenir; rompiendo el trayecto de la historia, encontrándole sentido al mundo. La experiencia valorada del hombre que busca ese «acontecer» desde su elección por un mundo donde un alter-yo se resiste a ser conceptualizado y a encerrarse en ideas o conceptos prefijados.

Un «neo-humanismo» como propuesta, debería fijarse la meta de acercarse más al poeta que al científico, al poema que al conocimiento, a la poesía que a la razón práctica kantiana; debe propugnar volver a sus orígenes, al nacimiento como tragedia desde que entendemos que la vida es arte y por ello existen múltiples actos: pasión, amor, dolor, sufrimiento, placer y por supuesto, pensar.

\section{Conclusiones}

Detrás de la obra de María Zambrano, hay muchas preocupaciones de carácter ético, político, social, filosófico, poético, religioso, pero sobretodo humano.

\section{(c) (1)(2)}

La Revista Estudios es editada por la Universidad de Costa Rica y se distribuye bajo una Licencia Creative Commons Atribución-NoComercial-CompartirIgual 3.0 Costa Rica. Para más información envíe un mensaje a revistaestudios.eeg@ucr.ac.cr. 
Revista Estudios, (36), 2018.

Junio 2018-Noviembre 2018

ISSN 1659-3316

Briones Yela Roberto Johann

Considero que; incluso, esta última categoría encierra ya las otras, pues la totalidad de las categorías -científicas o no-, se rigen por el ser del hombre o el acontecer cotidiano del mismo.

Desde esta comprensión, la filosofía de Zambrano responde a situaciones en las que las crisis actuales - de la ciencia, de las ciencias y por ende del hombre-, alcanzan incluso al pensamiento, dando la idea de agotamiento para aquello que se las necesita.

Entiendo que María Zambrano, desde su pensar, buscó remediar aquello que la filosofía dejó por mucho tiempo en la sombra, para sacarlo del silencio y la pereza y llevarlo hacia la luz.

Esto vale incluso para la pedagogía, donde mucho se ha hecho en "forma", pero dejando de lado; o incluso potenciando, aunque este mal o sea "nefasto", el fondo. Importante, entonces, destacar el trabajo fundamental del docente-pedagogo, para quien -según María Zambrano- las actitudes del aprendizaje son también motivo de reflexión, desde la vocación y mediación histórica del maestro.

En esta tarea, surgen circunstancias y figuras que se evolucionan en el proceso del pensar, presencias que se incorporaron a sus escritos dejando huellas y signos de lo que pensó, plasmó y defendió.

La razón poética, no es más que un camino donde la poesía busca la verdad de la vida y que para el pedagogo debería ser la educación, por vocación y por decisión; pues el pedagogo es como el poeta que no se cansa de recrear y exponer que la poesía es estar cerca de la vida y que busca el pensar unido al sentir para vivir.

\section{(c) (i) (2)}

La Revista Estudios es editada por la Universidad de Costa Rica y se distribuye bajo una Licencia Creative Commons Atribución-NoComercial-CompartirIgual 3.0 Costa Rica. Para más información envíe un mensaje a 


\section{BIBLIOGRAFÍA}

AAVV. (2015). Biblia de Jerusalem. Madrid: Desclé derBower.

Burckhardt, J. (2004). La cultura del renacimiento en Italia. Madrid: Akal.

Ferrater Mora, J. (2012). Diccionario de Filosofía. México: Atlante.

García, J. (2000). Diccionario de Filosofía. México: Edaf.

Han, B. (2012). La sociedad del cansancio. Barcelona: Editorial Herder.

Heidegger, M. \&. (2005). ¿Qué significa Pensar? Madrid: Trotta.

Heidegger, M. (1992). Holderlin y la esencia de la poesía (trad. Samuel Ramos). Buenos Aires: F.C.E.

Iza, V. (2016). El olvido de la Otredad en las relaciones económicas y el deterioro de la alteridad humana. En U. P. Salesiana, Desarrollo social y entornos empresariales en Ecuador (pág. 220). Guayaquil: Abya-Yala.

Janés, C. (agosto de 1984). La palabra poética en María Zambrano. Obtenido de cervantesvirtual.com: www.cervantesvirtual.com/research/la-palabrapoetica-en-maria-zambrano/f48db91f-9c90-43f8-8a25-63843b024cf8.pdf

Kristeller, P. (1993). El pensamiento renacentista y sus fuentes. Madrid: Fondo de cultura económica.

Larrosa, J. (2003). El ensayo y la escritura académica. Revista Propuesta Educativa, 60.

Levinas, E. (2004). Difícil Libertad (Gagarine et nous.Difficile liberté). Madrid: Caparros.

Nietzsche, F. (1973). Así habló Zaratustra. Madrid: Alianza Editorial.

Nietzsche, F. (2016). Las consideraciones intempestivas (1873-1876). Roma: Greenbooks editore.

\section{(c) (i) (2) (2)}

La Revista Estudios es editada por la Universidad de Costa Rica y se distribuye bajo una Licencia Creative Commons Atribución-NoComercial-Compartirlgual 3.0 Costa Rica. Para más información envíe un mensaje a 
Revista Estudios, (36), 2018.

Junio 2018-Noviembre 2018

ISSN 1659-3316

Briones Yela Roberto Johann

Niezstche, F. (2016). El nacimiento de la tragedia. Madrid: Edaf.

Sanchez-Gey, J. \&. (2011). María Zambrano, Filosofía y Educación: manuscritos. Barcelona: Editorial Club Universiatrio.

Sanchez-Gey, J. (2014). La educación en María Zambrano: su reflexión sobre la persona. La educación en María Zambrano: su reflexión sobre la persona (págs. 90-99). Madrid: Seminario María Zambrano.

Schiller, F. (2009). Lírica del pensamiento. Madrid: Hiperión.

Zambrano, M. (1977). Claros del Bosque. Barcelona: Seix Barral.

Zambrano, M. (2004). Los Bienaventurados. Madrid: Siruela.

Zambrano, M. (2015). Obras Completas (Vol. 1). Barcelona: Galaxia Gutenberg.

Zambrano, M. (2016). Obras Completas (Vol. 3). Barcelona: Galaxia Gutemberg.

Zuluaga, C. (2015). Nietzsche: una visión estética de la vida a través de la tragedia. EN-Clave Social, 76.

La Revista Estudios es editada por la Universidad de Costa Rica y se distribuye bajo una Licencia Creative Commons Atribución-NoComercial-CompartirIgual 3.0 Costa Rica. Para más información envíe un mensaje a revistaestudios.eeg@ucr.ac.cr. 